Rev. Latinoam. Psicopat. Fund., VI, 1, 7-12

Editorial

\title{
Para Pierre Fédida, meu amigo ${ }^{1}$
}

Roland Gori

Hoje é domingo. Pierre não me telefonará. Pierre não me telefonará mais. Ele morreu em Paris, na sexta-feira, $1^{\circ}$ de novembro. Mareike WolfFédida havia me deixado uma mensagem na véspera, me informando sobre a hospitalização de Pierre e sobre a gravidade de seu estado. Eu estava de férias e só encontrei a mensagem de Mareike na minha volta. Ao mesmo tempo, Danièle Brun e depois Edouard Zarifian, igualmente avisados por Mareike, também haviam me informado. Começou em seguida a ronda de todos os outros amigos vindos para ficarem juntos de Pierre após nossas chamadas telefônicas. Os íntimos, sempre os íntimos... e depois os círculos que aumentam como molduras circulares na superfície da água quando há um choque, um impacto ligado ao desaparecimento. Mas na lógica subjetiva o desaparecimento precede o impacto que aparece apenas no momento em que os vestígios lhe dão uma vida psíquica.

A vida psíquica é constituída pela memória do morto que não saberia reduzir-se à nudez objetiva dos acontecimentos. Pierre falava dessa "imaginação das formas" que faz com que a materialidade "da matéria psíquica” não se reduza ao mero "material clínico”. Entre os dois ele

1. A tradução é de Maria Vera Pompêo de Camargo Pacheco e a revisão técnica é do Prof. Dr. Mário Eduardo Costa Pereira, ambos do Laboratório de Psicopatologia Fundamental da UNICAMP. 
recorria ao que chamava de "capacidade alucinatória” da escuta do analista, para dar vida e movimento às formas. Mas para passar do material à matéria, do sono ao sonho, é necessário esse trabalho de luto que funda uma memória e ao qual os ritos, assim como as lembranças, fazem somente cortejo.

Pierre me telefonava freqüentemente aos domingos no final da manhã. Esse domingo eu senti necessidade de escrever. A escrita como o sonho participam do que Pierre chamava "a obra de sepultura". Por que desde essa manhã fiquei obcecado pela lembrança dessa canção de minha infância que minha mãe cantava e que nos fazia, todos dois, chorar? A “canção da órfã”, ela nos dizia. Não me lembro mais exatamente das outras palavras, mas apenas da melodia de um refrão que repete incansavelmente que "hoje é domingo" e que fala de "rosas brancas para ti mamãe...”

Como o desaparecimento de Pierre, tão imperial, figura paternal e fraternal em majestade, pode fazer reviver uma lembrança ligada à imagem materna?

Creio que em primeiro lugar é por sua generosidade, sua imensa generosidade intelectual, espiritual e afetiva. Pensando nele, reencontrei também a lembrança das pinturas do Trecento e Quattrocento representando as Virgens de Misericórdia, sob o manto das quais refugiava-se todo o povo humilde da humanidade. Cada conferência de Pierre, as defesas de tese ou de $\mathrm{HDR}^{2}$ das quais participávamos juntos, seus artigos e suas obras, davam-me sempre a mesma impressão: Pierre debulhava múltiplos seixos, idéias, pensamentos e observações, com os quais uma multidão de pessoas iam encontrar seus próprios caminhos. Ele propagava idéias generosamente, palavras que semeavam os espíritos e o coração. Quantas teses ele gerou dessa forma?

E, além disso, havia a voz. Essa voz quente, ampla e profunda que carregava idéias com força e elegância. Essa voz hoje, me faz uma falta cruel. Havia também nossas longas e íntimas discussões sobre nossos projetos, sobre a psicanálise, sobre as alegrias e as dores da vida. Havia nossos debates e, às vezes, nossos desacordos. Por exemplo, em setembro de 2001 em Lyon, por ocasião de uma jornada de trabalho organizada por Jacques Hochmann sobre o tema “O que cura na psicoterapia?”, seqüência de um Fórum Diderot, Pierre não havia aprovado minha aproximação entre a retórica e a psicanálise. Nós discutimos sobre isso com amizade e confiança. Ou ainda por ocasião do último colóquio sobre as paixões, organizado por Didier Lauru e Alain Vanier em 21 de setembro de 2002, no quadro do Espaço analítico; Pierre designava a paixão como um enclave de Eros, um objeto psicopatológico sobre o qual ele não estava conven-

2. Habilitation à la Direction de Recherches: título da Universidade francesa, obtido após o doutorado, capacitando seu detentor a dirigir teses e pesquisas universitárias. (N. da T.) 
cido de que poderíamos fazer uma metapsicologia. Esse dia ele havia feito no Espaço, uma fantástica conferência sobre Erixímaco e a medicina. E em seguida à noite, depois dos colóquios, havia os jantares amigáveis ao longo dos quais Pierre apresentava-se brilhante, elegante, cheio de charme e de gentileza.

Pierre era um homem de envergadura ampla e profunda ao mesmo tempo, reservado e disponível, discreto e aberto, modesto e potente. Essa palavra envergadura impõe-se a mim cada vez que penso nele. É uma palavra de origem marinha, que vem de "verga” para designar o mastro que mantém as velas, permitindo a navegação. Hoje as velas estão a meio-pau. Nós o sepultamos nesta sexta-feira, 8 de novembro, no Cemitério de Montparnasse, na presença de sua família e de uma grande multidão de amigos, de colegas e de alunos.

Pierre não se deixava enclausurar, marcando com sua presença os lugares e os seres junto aos quais ele se mantinha.

Era também um passante, um homem que dava movimento e melodia ao ser vivo. Escrevia que "o luto é a colocação em movimento do mundo" e pela “construção de sepultura”, pela "obra da sepultura”, ele nos convidou ao sonho: "pois sonhar é a única maneira de pensar em nossos mortos”. O sonho sim, mas a escrita também... a escrita, quando é deduzida do trabalho do sonho. Ele havia me dito a respeito da perda de um ente querido: "Permita ao irmão mais velho lhe dizer que é na escrita que você o honrará”.

Pierre tinha uma enorme coragem e não suportava queixas. A queixa lhe parecia agressiva e sem pudor. Sempre recusou lamentar-se ou que se lamentassem para ele, muito embora tivesse enorme cuidado com o sofrimento dos outros. Pierre era um fidalgo, um grande fidalgo do pensamento, da inteligência e do coração. Essa postura de enunciação está inscrita em toda sua obra. Elisabeth Roudinesco encontrou as palavras exatas quando, anunciando seu desaparecimento no Le Monde, o designou como uma "grande figura da universidade e da psicanálise”. Pierre era um grande pensador, um intelectual, autor de uma obra abundante e fecunda consagrada à psicanálise, à Universidade e aos debates maiores de nosso tempo.

Ele havia acabado de fundar o Instituto do Pensamento Contemporâneo, com Júlia Kristeva, Dominique Lecourt e François Julien. Cada um dos sítios onde inscreveu seu pensamento e seu trabalho poderá legitimamente reivindicar uma parte de sua herança intelectual, mas conviria a todos reconhecer com decência e respeito, que ele não se deixava encravar em nenhum deles porque os transcendia a todos. A esse propósito, Alain Vanier fazia-me delicadamente notar a posição "paradoxal” de Pierre em relação à instituição: ao mesmo tempo em que marcava profundamente cada um dos sítios onde seu trabalho se inscrevia, ao mesmo tempo em que ocupava as mais altas responsabilidades em cada lugar institucional onde trabalhava, ele manifestava sem cessar uma 
preocupação com a abertura e com afinidades voltadas para o exterior. Cioso de sua liberdade, Pierre a oferecia também à seus amigos e à seus alunos.

Paralelamente a estudos de filosofia sancionados por um concurso em 1962, Pierre completou os estudos de psicologia primeiramente em Lyon e depois em Montpellier. Durante seu serviço militar, trabalha como psicólogo clínico no departamento de neurologia do Hospital Militar de Lyon. Mais tarde leciona filosofia e psicopedagogia na Escola Normal e, por fim, psicologia na faculdade de Letras e Ciências Humanas em Lyon. Logo após, ele adquire junto a Ludwig Biswanger, em Kreuzlingen, uma sólida formação clínica e teórica em psicopatologia de orientação fenomenológica. Faz em seguida uma análise didática com Georges Favez e inscreve seu trajeto psicanalítico no quadro da Associação Psicanalítica da França, a qual presidirá de 1988 a 1990. Sua audiência internacional na I.P.A. jamais o impedirá de relacionar-se com os autores lacanianos e aceitar o debate com os analistas não pertencentes à I.P.A. Funda assim uma comunidade freudiana sem afiliação à residência institucional e que ele reconhece tanto quanto ela o reconhece.

Na Universidade, Pierre Fédida foi nomeado, em 1967, para ocupar a função de Mestre Assistente junto a Juliette Favez-Boutonier. Em 1969, ele participa da criação da $\mathrm{UFR}^{3}$ de Ciências Humanas Clínicas de Paris 7 - Censier. Inicialmente no quadro do Laboratório de Psicanálise de Jean Laplanche e mais tarde, em 1989, na direção de seu próprio laboratório de Psicopatologia Fundamental, ele vai realizar uma obra considerável e formar numerosos professores-pesquisadores em psicopatologia e psicanálise.

Na Universidade de Paris 7, ele ocupa as mais altas funções científicas e políticas (Vice-Presidente da Universidade, Presidente do Conselho Científico, diretor da formação em doutorado, Diretor da UFR...). Ao longo desses últimos anos, ele vai consagrar-se mais particularmente à concepção e à implantação do Centro de Estudos do Vivo. A iniciativa é genial: colocar em debate ético e filosófico as pesquisas e interrogações das ciências do ser vivo, resultantes da rápida mutação tecnológica de nossa época. Esses encontros entre cientistas, filósofos, juristas..., e psicanalistas realizam-se mais especificamente nos "Fórum Diderot”, organizados pelo Centro de Estudos do Vivo, dirigido por Pierre Fédida e pela Associação Diderot, presidida por Dominique Lecourt. Os trabalhos do Fórum de Diderot dão lugar a numerosas publicações pela editora Presses Universitaire de France. Citemos entre outras: “O embrião humano é humano?”, “O fim da vida, quem decide sobre isso?” (1996), “Amanhã, os psicotrópicos?” (1998), “O que cura na psicoterapia?” (2000), “Pode-se estar vivo na África?” (2000), “Cuidar sem riscos?” (2001).

3. Unité de Formation et Recherche: Unidade de formação e pesquisa. (N. da T.) 
Pierre Fédida era um universitário, um psicanalista, um clínico e um teórico, um pensador internacionalmente reconhecido. Ele animou seminários, deu conferências e realizou missões em inúmeros países estrangeiros, lá também com uma amplitude e uma profundidade excepcionais. Um exemplo entre outros: a rede de pesquisa latino-americana em psicopatologia fundamental criou um Prêmio Fédida recompensando os melhores trabalhos de pesquisa sul-americanos de nossa disciplina. Mas o engajamento de Pierre Fédida não era somente científico, era também político e ético: Pierre engajava-se cada vez que lhe parecesse necessário defender o humano e os valores humanistas.

Suas responsabilidades editoriais foram amplas e numerosas, de início com Ramsay e depois com a Presses Universitaire de France. Ele fundou e co-dirigiu com Daniel Widlöcher a Revue Internationale de Psychopathologie, que tornou-se, mais tarde, as Monographies de la Revue Internationale de Psychopathologie. Participou, nos anos 1990, da fundação da revista L'Inactuel com Calmann-Levy.

Sua obra científica é considerável. Conta-se cerca de uma dúzia de obras, entre outras: Corpo do vazio e espaço de sessão (1977), A ausência (1978), Crise e contratransferência (1992), O sítio do estrangeiro (1995) e mais recentemente Por onde começa o corpo humano (2000) e Dos benefícios da depressão (2000). Dirigiu inúmeras obras coletivas e escreveu mais de duzentos textos e artigos publicados nas principais revistas francesas e internacionais de psicopatologia, de psiquiatria e de psicanálise.

Essa obra científica conferiu-lhe uma audiência internacional que se estendeu bem além das fronteiras disciplinares tradicionais. Pierre Fédida era um homem de cultura e na cultura. Universitário excepcional, ele serviu por sua envergadura à causa da Universidade e à da Psicanálise.

Eu tive a chance de participar com ele de missões de pareceres científicos sobretudo no quadro do Conselho Nacional das Universidades e por ocasião de avaliação dos perfis científicos com objetivo de defesa de teses e de HDR. Nós juntos nos mostramos muito preocupados com a necessidade de definir uma política para a pesquisa e o ensino da psicopatologia que respeite ao mesmo tempo as exigências da Universidade e as da psicanálise. Nossa amizade e a ajuda eficaz de André Sirota e de Mareike Wolf-Fédida, assim como o apoio de amigos próximos e colegas, fizeram o resto: nós criamos o Seminário Inter-Universitário e de Pesquisa em Psicopatologia e Psicanálise (SIUERPP), em 2000. Nesse verão, Dominique Cupa realizou uma entrevista com Pierre Fédida e comigo que acaba de ser publicada no Carnet PSY. O SIUERPP reúne uma centena de professorespesquisadores de Psicopatologia de departamentos de psicologia, representativos de todas as correntes da psicopatologia e da psicanálise. Mas também é verdade que essa psicopatologia, como escrevia Pierre em seu último livro sobre a 
compreensão dos processos da depressão, “só pode ser compreendida dentro de seu conceito psicanalítico”.

O desaparecimento de Pierre Fédida é para nós uma imensa perda. Possamos nós, como ele sem dúvida teria desejado, prosseguir esse trabalho e, assim fazendo, construir essa "obra de sepultura" à partir da qual anima-se e forma-se o ser vivo. Pois tal é o trabalho que funda e honra o psíquico, fora do qual se encontram o traumatismo, a barbárie e o desumano.

Rendemos homenagem à sua obra e num outro tempo e num outro lugar. E para concluir citarei esta frase de um artigo de Pierre, publicado em 1970 na Nouvelle Revue de Psychanalyse e intitulado "A relíquia e o trabalho do luto". "A despeito de um saber sobre a separação, é preciso acreditar que alguma coisa subsiste”. 